\title{
O PDE e as metas do PAR para a formação de professores da educação básica
}

\author{
Marilda Pasqual Schneider* \\ Elton Luiz Nardi** \\ Zenilde Durli****
}

\section{Resumo}

Este trabalho analisa a política de regulação do Plano de Desenvolvimento da Educação (PDE) considerando as ações do Plano de Ações Articuladas (PAR) como indutoras de melhoria da qualidade na educação básica. Por meio de exame documental, focaliza as ações de formação inicial e continuada dos professores da educação básica previstas no PAR de vinte municípios da mesorregião oeste do estado de Santa Catarina, considerados prioritários para recebimento de apoio técnico e ou financeiro do MEC. Põe em evidência a atuação regulatória do Estado na projeção do PAR, com tendência à responsabilização dos municipios no atendimento às metas educacionais para a formação de professores. Vislumbra quadro preocupante no tocante à melhoria da qualidade educativa desses municípios uma vez que as ações propostas buscam responder, preponderantemente, às indicações do MEC sem necessária correspondência com as especificidades locais.

Palavras-chave: Política educacional. PDE. Metas e ações do PAR. Formação de professores da educação básica.

\section{The PDE and the goals of par for the teachers'formation of basic education Abstract}

This study analyses the regulatory policy of the Plan of Education's Development (PDE) considering the actions of the Articulated Plan of Actions (PAR) as the inductor of improving quality in basic education. Through document review, focuses on the actions

* Doutora em Educação pela Universidade Federal de Santa Catarina; Professora do Programa de PósGraduação em Educação da Universidade do Oeste de Santa Catarina (Unoesc). E-mail: marilda.schneider@unoesc.edu.br.

*** Doutor em Educação, Unisinos; Professor do Programa de Pós-Graduação em Educação da Universidade do Oeste de Santa Catarina (Unoesc). E-mail: elton.nardi@unoesc.edu.br

**** Doutora em Educação, Universidade Federal de Santa Catarina; Professora da Universidade Federal da Fronteira Sul (UFFS). E-mail: zenilde.durli@uffs.edu.br 
of initial and recurrent teachers' formation of basic education provided in the PAR of twenty municipalities of West mesoregion of Santa Catarina State, considered as priorities for receiving technical and / or financial support from MEC. It highlights the strong regulatory actions of the State in the projection of the $P A R$, with a tendency to give responsibility to municipalities in complying with educational goals for the teachers' formation. It also foresees a worrying picture regarding the improvement of educational quality of these municipalities since the proposed actions seek to respond, mainly, on indications of MEC without necessary correspondence with real local needs. Keywords: Educational policy. PDE. Goals and actions of the PAR. Teachers' formation of basic education.

\section{El PDE y las metas del par para la formación de profesores de la educación básica Resumen}

Este trabajo analiza la política de regulación del Plan de Desenvolvimiento de la Educación (PDE) considerando las acciones del Plan de Acciones Articuladas (PAR) como inductoras de mejoramientos de la cualidad en la educación básica. Mediante examen documental, foca las acciones de formación inicial y continuada de los profesores de la educación básica previstas en el PAR de veinte municipios de la meso región oeste del estado de Santa Catarina, considerados prioritarios para recibir apoyo técnico y o apoyo financiero del MEC. Pone en evidencia la fuerte actuación reguladora del Estado el la proyección del $P A R$, con tendencia a responsabilizar los municipios en el atendimiento de las metas educacionales para la formación de profesores. Vislumbra situación preocupante a lo que se refiere a la mejoría de la cualidad educativa de estos municipios una vez que las acciones propuestas buscan responder, preponderantemente, las indicaciones del MEC sin la necesaria correspondencia con las reales necesidades locales.

Palabras clave: Política educativa. PDE. Metas y acciones del PAR. Formación de los profesores de la educación básica.

\section{Introdução}

As políticas educacionais das últimas décadas têm evidenciado, de um lado, forte tendência ao fortalecimento do papel do Estado como produtor e regulador das mudanças nacionais, principalmente na educação básica (BARROSO, 2003, 2004, 2005; OLIVEIRA, 2005; CASTRO, 2007) e, de outro, a responsabilização de estados e municípios pela implementação e pelos resultados pretendidos com as reformas educacionais em curso (MARTINS, 2001; AZEVEDO, 2002; KRAWCZYK, 2005).

Nesse contexto, foi lançado no ano de 2007 o Plano de Desenvolvimento da Educação (PDE), com o propósito anunciado de tornar-se instrumento de prestação de contas da qualidade de ensino. Criado para abrigar uma série de ações já existen- 
tes e outras novas, gestadas e executadas pelo próprio Ministério da Educação (MEC), é considerado um grande guarda-chuva sendo anunciado como o "PAC" da educação. Constitui-se, pois, de um conjunto de programas e medidas reunidas, transformadas em um "Plano", que assume "inclusive na denominação, a agenda do 'Compromisso Todos pela Educação' (SAVIANI, 2007, p. 1243).'

Anunciado como "mais um passo em direção à construção de uma resposta institucional [...]" (BRASIL, 2007a, p.5), este Plano adjudica ao governo federal o papel de regulador das desigualdades regionais e municipais por meio de assistência técnica e/ou financeira para implantação e execução dos programas e medidas planeadas e da construção de instrumentos de avaliação focalizados numa política geral e abrangente. Tem como intencionalidade declarada o alcance de uma educação de qualidade para todos.

A regulação pretendida pelo poder central por meio do PDE, porquanto centrada em nível nacional e caracterizada pelo "modo como as autoridades públicas [...] exercem a coordenação, controlo e a influência sobre o sistema educativo" (BARROSO, 2004, p.22), constitui-se, em uma regulação de tipo institucional. Considerando, no entanto, os diferentes sujeitos, instâncias e interesses implicados na implantação de um programa ou ação, compreende-se a regulação do sistema educativo como um "processo compósito que resulta mais da regulação das regulações do que do controlo directo da aplicação de uma regra sobre acção dos 'resultados'" (BARROSO, 2005, p. 733). Por essa explicação, considera-se que, embora o Estado se constitua em fonte essencial de regulação, ele não é a única; são múltiplas as regulações, e diferentes os seus niveis a que o sistema educativo está sujeito.

A despeito de o Estado não se constituir em única fonte de regulação, visto serem múltiplas as que o sistema educativo está sujeito, interessa-nos evidenciar as estratégias pela qual a regulação institucional adjucada pelo PDE opera no âmbito dos municípios, nomeadamente no que se refere às políticas de formação de professores.

Desde o lançamento do PDE, as transferências voluntárias e de assistência técnica do MEC aos municípios estão vinculadas à elaboração de um plano municipal, com caráter de PDE local (SAVIANI, 2009), denominado Plano de Ações Articuladas (PAR). A elaboração do PAR prevê auxílio técnico de consultores do MEC aos gestores municipais, consoante resultados de indicadores de qualidade educacional das escolas e dos sistemas de ensino.

1 Trata-se do "Todos pela Educação", movimento lançado em setembro de 2006, com a finalidade precípua de contribuir para que o país consiga garantir educação de qualidade para todos os brasileiros, por meio da união de esforços. Congrega a sociedade civil, a iniciativa privada, organizações sociais e de educadores e gestores públicos de educação. À frente do seu processo de organização esteve um Conselho de Governança, constituído predominantemente de empresários, contando com a participação e articulação do MEC. (MOVIMENTO TODOS PELA EDUCAÇÃO, [2006]). 
Como um Plano geral e abrangente, cuja efetividade depende das unidades subnacionais e das escolas, entendemos que o controle operado pela via do PAR sobre as ações das diferentes dimensões, traduz um processo de regulação na medida em que orienta condutas, define as "regras do jogo" e exerce coordenação e controle, objetivados e institucionalizados em dispositivos materiais, legais e técnicos promovidos pelo Estado (MAROY, 2011).

Como um processo múltiplo, reconhecemos que esta regulação mescla-se com regras e medidas construídas e mobilizadas no âmbito local tendo em vista a resolução de problemas existentes neste âmbito. Para Maroy (2011), a interação entre esta dimensão autônoma de regulação (local) e a referida regulação institucional compõe um quadro de multirregulação (BARROSO, 2004) e de mobilização de estratégias indutivas, visando à conquista de adesão a determinados projetos.

Considerando o contexto apresentado, neste trabalho intencionamos explorar essa política de regulação institucional operada pelo Estado através do PDE, considerando as ações do PAR nos municipios. Concretamente, o objetivo consiste em analisar o modus operandi do PAR pelo estudo das ações destinadas à formação inicial e continuada dos professores em municípios considerados prioritários pelo Ministério da Educação (MEC) para receber auxílio técnico e/ou financeiro, perspectivando possibilidades de alcance de soluções às necessidades locais.

Tomamos o PAR como uma política de indução do PDE nos municípios e de regulação das ações propostas, inclusive considerando que a configuração, o processo de elaboração e abrangência que assume no contexto das políticas educacionais, conferem ao PAR a condição de modus operandi do PDE.

Assim, nosso estudo tem como ponto de partida a exploração do processo de elaboração do PAR, pela análise documental, nas suas três fases: a construção do diagnóstico, a elaboração do plano de ação e, por fim, a análise e aprovação do seu mérito qualitativo.

Por meio do PAR, o gestor descreve o tipo de apoio que o município necessita no âmbito educacional, detalhando um conjunto de ações estruturadas em quatro grandes dimensões, quais sejam: 1) gestão educacional; 2) formação dos professores e dos profissionais de serviços e apoio escolar; 3) práticas pedagógicas e avaliação; e 4) infraestrutura física e recursos pedagógicos. 0 suporte técnico oferecido pelo MEC se destina, majoritariamente, aos municípios considerados prioritários em vista dos resultados educacionais obtidos no IDEB (Índice de Desenvolvimento da Educação Básica).

Com o intuito de apreender a materialidade das fases de elaboração em torno da Dimensão 2, especificamente no tocante à formação inicial e continuada de professores para a educação infantil e ensino fundamental, analisamos o PAR de 20 municípios situados na mesorregião oeste do estado de Santa Catarina, considerados prioritários pelo MEC para recebimento de apoio técnico e /ou financeiro. 


\section{Plano de Ações Articuladas: regulação pela via do PDE}

Articulado ao PDE está o Plano de Metas Compromisso Todos pela Educação, estabelecido no Decreto Presidencial n 6.094, de 24 de abril de 2007 (BRASIL, 2007b), como um "programa estratégico do PDE" (BRASIL, 2009a, p.2). Pelo Plano de Metas o MEC promete apoio técnico ou financeiro aos municípios, estados e ao Distrito Federal, prioritariamente àqueles com baixa classificação no IDEB, desde que estes assinem o Termo de Adesão ao Compromisso Todos pela Educação. Fato que ocorreu por parte de todos os municípios brasileiros, até meados de 2008.

0 apoio técnico do MEC destina-se à disponibilização de uma "equipe técnica para, em conjunto com os dirigentes municipais, elaborar um diagnóstico da situação educacional local e propor o Plano de Ações Articuladas (PAR) para a educação básica" (BRASIL, [2008], p.2), configurando um planejamento multidimensional de responsabilidade dos municípios brasileiros para 0 período de 2008 a 2011. 0 intento governamental é assegurar o cumprimento das 28 diretrizes previstas no Plano de Metas Compromisso Todos pela Educação, constantes do art. $2^{\circ}$ do Decreto n 6.094/2007 (BRASIL, 2007b).

Tomando como escopo as metas estabelecidas no Decreto, o MEC criou um manual de elaboração do PAR - Instrumento de Campo (BRASIL, 2008a), no qual estão previstas as áreas de atuação, a caracterização das ações em cada uma das quatro dimensões de atuação dos municípios e os indicadores específicos de qualidade. Consubstanciado no manual, o gestor elabora o diagnóstico da situação do município no tocante a cada dimensão, passando, então, à elaboração do plano de ação.

0 MEC fornece um conjunto de orientações pré-qualificadas que subsidiam elaboração do diagnóstico, tendo em vista a situação do município nas quatro grandes dimensões do PAR.

No tocante à Dimensão 2 - Formação dos Professores e dos Profissionais de Serviços e Apoio Escolar - são delimitadas cinco áreas consideradas prioritárias pelo MEC para avaliação dos municipios. ${ }^{2} 0$ Quadro 1 sintetiza os indicadores de quatro áreas $(1,2,3$ e 4$)$ dessa dimensão, as quais têm relação direta com nosso objeto de estudo.

2 A Área 5, destinada à Formação do Profissional de Serviços e Apoio Escolar não foi foco da pesquisa, visto pertencer a um segmento complementar do universo de investigação. 
Quadro 1: Indicadores de referência da Dimensão 2 do Plano de Ações Articuladas

\begin{tabular}{|c|c|}
\hline \multicolumn{2}{|c|}{ Área 1 - Formação inicial de Professores da Educação Básica } \\
\hline Indicador 1 & Qualificação dos professores que atuam nas creches \\
\hline Indicador 2 & Qualificação dos professores que atuam na pré-escola \\
\hline Indicador 3 & $\begin{array}{l}\text { Qualificação dos professores que atuam nas séries iniciais do ensino } \\
\text { fundamental }\end{array}$ \\
\hline Indicador 4 & $\begin{array}{l}\text { Qualificação dos professores que atuam nos anos/séries finais do ensino } \\
\text { fundamental }\end{array}$ \\
\hline \multicolumn{2}{|c|}{ Área 2 - Formação Continuada de Professores da Educação Básica } \\
\hline Indicador 1 & $\begin{array}{l}\text { Existência e implementação de políticas para a formação continuada de } \\
\text { professores que atuam na Educação Infantil. }\end{array}$ \\
\hline Indicador 2 & $\begin{array}{l}\text { Existência e implementação de políticas para a formação continuada de } \\
\text { professores que atuam na Educação Infantil. }\end{array}$ \\
\hline Indicador 3 & $\begin{array}{l}\text { Existência e implementação de políticas para a formação continuada de } \\
\text { professores, que visem a melhoria da qualidade de aprendizagem da } \\
\text { leitura/escrita e matemática nos anos/séries finais do ensino } \\
\text { fundamental. }\end{array}$ \\
\hline \multicolumn{2}{|c|}{$\begin{array}{l}\text { Área 3- Formação de Professores da Educação Básica para atuação em educação especial, } \\
\text { escolas do campo, comunidades Quilombolas ou Indígenas }\end{array}$} \\
\hline Indicador 1 & $\begin{array}{l}\text { Qualificação dos professores que atuam em educação especial, escolas } \\
\text { do campo, comunidades quilombolas ou indigenas. }\end{array}$ \\
\hline \multicolumn{2}{|c|}{$\begin{array}{l}\text { Área } 4 \text { - Formação inicial e continuada de professores da Educação Básica para } \\
\text { cumprimento da Lei } 10.639 / 03^{3}\end{array}$} \\
\hline Indicador 1 & $\begin{array}{l}\text { Existência e implementação de políticas para a formação inicial e } \\
\text { continuada de professores, que visem a implementação da Lei } 10.639 \\
\text { de } 09 \text { de janeiro de } 2003 \text {. }\end{array}$ \\
\hline
\end{tabular}

Fonte: Elaborado com base em Brasil (2008a).

Os indicadores de cada área são pontuados pelo município em conformidade aos critérios de avaliação dispostos pelo MEC no documento orientador, em uma escala de notas que pode ir de um a quatro pontos. Desse modo, o diagnóstico da realidade educacional local é constituído pela pontuação atribuída a cada um dos indicadores que compõem as áreas daquela dimensão. Adiante são apresentados os critérios de avaliação disponíveis aos gestores para atribuição de pontuação das dimensões compósitas da Dimensão 2.

3 Refere-se à introdução, nos currículos escolares, da História da cultura afro-brasileira. 
A dinâmica do PAR compreende, ainda, a elaboração do plano de ação, também sob a responsabilidade do município, momento em que consultores são disponibilizados pelo MEC para prestar assistência técnica na sua formulação. Consoante destacamos, a prioridade para essa assistência é determinada pelo resultado do IDEB de cada município. A sua elaboração vem subsidiada pelos documentos "Orientações para Elaboração do Plano de Ações Articuladas" (BRASIL, 2009a) e "Guia Prático de Ações" (BRASIL, 2009b), que orientam a definição de ações que comporão o PAR dos municípios.

Por fim, o PAR é submetido a uma Comissão Técnica (CT) responsável pela aprovação do mérito qualitativo do plano, considerando os seguintes fatores: I) disponibilidade de recursos orçamentários e financeiros, para sua implementação; II) capacidade operacional do Fundo Nacional de Desenvolvimento Educacional (FNDE) e do ente federativo proponente; III) condições efetivas de aceleração do desenvolvimento do IDEB local. ${ }^{4}$

A leitura minuciosa da dinâmica de elaboração do PAR e de sua metodologia já torna possível depreender, ao menos, duas constatações. A primeira delas refere-se à estratégia de construção do plano por meio de orientações padronizadas. Porquanto impondo uniformização na construção do diagnóstico, das áreas de abrangência de cada dimensão, dos respectivos indicadores de avaliação e das ações de cada indicador, o MEC decide o que é importante e, portanto, passivel de apoio técnico ou financeiro. Nesse sentido, as necessidades dos municípios no tocante à formação inicial e continuada de seus professores, tornam-se, em boa medida, reféns das coincidências nas prioridades estabelecidas pelo Ministério.

A segunda constatação refere-se ao caráter descentralizador da implementação dessa política pública, que passa a responsabilizar o município, mais diretamente, pelos resultados educacionais. Pela adesão ao "Plano de Metas Compromisso Todos pela Educação" (BRASIL, 2007b), o município se compromete a cumprir as ações propostas no PAR e a divulgar a evolução dos dados educacionais à população local de modo a promover o controle social das ações.

Essa dinâmica de elaboração do PAR e de sua metodologia, não possibilita aos municípios a indicação de outras metas e ações de formação que não as do conjunto definido pelo MEC. No entanto, são-lhe imputadas todas as responsabilidades no alcance dos resultados. Ora, um processo como esse, configura uma modalidade de descentralização de encargos executivos que preserva a decisão no centro, conformando condições de regulação.

Observe-se que o fato de os municípios brasileiros serem entes federativos autônomos, com autoridade política soberana, impõe que a parte interessada na efetivação de

4 A Resolução CD/FNDE $\mathrm{n}^{\circ}$ 29, de 20 de junho de 2007 (BRASIL, 2007c) estabelece os critérios, os parâmetros e os procedimentos para operacionalização da assistência financeira suplementar e voluntária a projetos educacionais, no âmbito do Compromisso Todos pela Educação, no exercício de 2007. 
um determinado modelo de descentralização, como o referido, conquiste a sua adesão, o que justifica a mobilização de estratégias indutoras. Essas estratégias também contribuem para fazer face às forças políticas locais que podem obstaculizar a adesão, forças estas que não raro implicam interesses em jogo na esfera política (COHN, 1998).

Como sublinha Arretche (1999), estratégias eficientemente desenhadas são mobilizadas para compensar eventuais forças promotoras de constrangimentos existentes nos municípios. No caso aqui estudado, alcançada a adesão dos municípios e garantido o processo de planejamento via PAR, a regulação estendida à execução de ações conforma este modelo de descentralização e responsabiliza os municípios no campo da formação dos profissionais do magistério da Educação Básica.

\section{Formação de professores: prioridades na mesorregião oeste catarinense}

Tendo em conta os objetivos do estudo, efetuamos análise do PAR de 20 municípios da mesorregião oeste do estado de Santa Catarina, nomeadamente aqueles definidos como prioritários para o recebimento de auxilio técnico e/ou financeiro por parte da União, tendo em vista os resultados obtidos no IDEB ${ }^{5}$.

Dado que a pesquisa ocorreu no ano de 2010, foram considerados os municípios relacionados como prioritários pelas Resoluções CD/FNDE/ n 47/2007 (BRASIL, 2007d) e n 46/2008 (BRASIL, 2008b). 0 intuito, na análise dos documentos do PAR destes municípios, foi o de verificar quais metas e ações foram definidas como prioritárias e as condições de sua execução.

A mesorregião oeste de Santa Catarina é formada por um conjunto de 118 (cento e dezoito) municípios. A extensiva maioria desses municípios conta com população de até 10.000 habitantes, tendo como principal atividade econômica a agricultura familiar. As já frágeis condições de desenvolvimento econômico são acentuadas pela dificuldade de inserção das suas pequenas propriedades rurais no mercado altamente competitivo e pelos déficits educacionais.

Ao longo tempo, cultivaram-se representações imagéticas e discursivas a respeito da região como um lugar periférico, desconhecido e à margem da comunhão nacional. 0 discurso corrente estereotipado estabeleceu uma relação de dependência que inibiu a autodeterminação e sugou a força política do lugar até por volta do final do século passado. Atualmente, por força do impulso econômico promovido pela ascensão de agroindústrias, a região estabelece paulatinamente uma nova rela-

50 IDEB é calculado em avaliações bianuais sendo composto pelo resultado obtido pelos alunos de $4^{\text {a }}$ série $/ 5^{\circ}$ ano, $8^{\text {a }}$ série $/ 9^{\circ}$ ano do ensino fundamental e de $3^{\text {a }}$ série do ensino médio na Prova Brasil e pela taxa de aprovação escolar dessas séries. 
ção com o restante do estado e do país, ainda que preserve, em alguma medida, raizes de uma tradição política conservadora.

De acordo com dados dos censos do IBGE, entre os anos de 1991 e 1996 o crescimento da população total do estado foi de 7,3\%, enquanto o da mesorregião foi de 1\%. Já entre os anos de 1996 e 2000, a mesorregião teve um crescimento populacional de $2 \%$, muito abaixo do observado no estado, que foi de $9,9 \%$.

No âmbito governamental, estes municípios empenham-se na busca de recursos nas esferas estadual e federal como alternativa de financiamento de politicas locais que dificilmente seriam implementadas com os escassos recursos próprios.

Em relação à educação, dados do Instituto Nacional de Estudos e Pesquisas Educacionais Anísio Teixeira (INEP), de 2010, informam que os municípios pesquisados respondem por aproximadamente $40 \%$ do atendimento da educação básica da região e cobrem cerca de $92 \%$ das matrículas na educação infantil e $43 \%$ no ensino fundamental regular, conforme demonstram os dados da Tabela 1.

Tabela 1: Matrícula inicial da educação básica em 2010, por dependência administrativa - Santa Catarina e mesorregião oeste do estado de SC.

\begin{tabular}{|c|c|c|c|c|c|c|c|c|c|c|c|}
\hline & \multirow{3}{*}{$\begin{array}{l}\text { Dtepen } \\
\text { - } \\
\text { dência } \\
\text { Adm. }\end{array}$} & \multirow{2}{*}{\multicolumn{2}{|c|}{$\begin{array}{l}\text { Educação } \\
\text { Infantil }\end{array}$}} & \multirow{2}{*}{\multicolumn{2}{|c|}{$\begin{array}{l}\text { Ensino } \\
\text { Fundamental }\end{array}$}} & \multirow{3}{*}{$\begin{array}{l}\text { Ensin } \\
0 \\
\text { Médi } \\
0\end{array}$} & \multirow{3}{*}{$\begin{array}{c}\text { Ed. } \\
\text { Profissi } \\
\text { o-nal } \\
\text { (Nivel } \\
\text { Técnico } \\
\text { ) }\end{array}$} & \multicolumn{4}{|c|}{$\begin{array}{c}\text { Educação de } \\
\text { Jovens e Adultos - EJA }\end{array}$} \\
\hline & & & & & & & & \multicolumn{2}{|c|}{ Presencial } & \multicolumn{2}{|c|}{ Semi-presencial } \\
\hline & & $\begin{array}{l}\text { Crech } \\
\text { te }\end{array}$ & $\begin{array}{l}\text { Pré- } \\
\text { Escol } \\
\text { a }\end{array}$ & $\begin{array}{c}\text { Anos } \\
\text { iniciai } \\
\mathrm{s}\end{array}$ & $\begin{array}{l}\text { Anos } \\
\text { finais }\end{array}$ & & & $\begin{array}{l}\text { Fund } \\
\text { a- } \\
\text { ment } \\
\text { al }\end{array}$ & $\begin{array}{l}\text { Médi } \\
0\end{array}$ & $\begin{array}{c}\text { Fund } \\
\text { a- } \\
\text { ment } \\
\text { al }\end{array}$ & Médio \\
\hline \multirow{5}{*}{ SC } & $\begin{array}{c}\text { Estadu } \\
\text { al }\end{array}$ & 67 & 82 & $\begin{array}{c}134.1 \\
64 \\
\end{array}$ & $\begin{array}{c}246.7 \\
03 \\
\end{array}$ & $\begin{array}{c}208.1 \\
98 \\
\end{array}$ & 9.385 & $\begin{array}{c}22.07 \\
5 \\
\end{array}$ & $\begin{array}{c}38.39 \\
2 \\
\end{array}$ & 1.227 & 2.386 \\
\hline & Federal & 153 & 101 & 342 & 293 & 3.606 & 5.466 & 0 & 227 & 62 & 0 \\
\hline & $\begin{array}{l}\text { Munici } \\
\text { pal }\end{array}$ & $\begin{array}{c}88.86 \\
5\end{array}$ & $\begin{array}{c}128.3 \\
65\end{array}$ & $\begin{array}{c}241.4 \\
28\end{array}$ & $\begin{array}{c}166.1 \\
09\end{array}$ & 1.216 & 0 & $\begin{array}{c}14.64 \\
5\end{array}$ & 2.828 & 7.567 & 119 \\
\hline & $\begin{array}{c}\text { Privad } \\
\text { a }\end{array}$ & $\begin{array}{c}22.96 \\
9\end{array}$ & $\begin{array}{c}24.36 \\
6\end{array}$ & $\begin{array}{c}42.65 \\
6\end{array}$ & $\begin{array}{c}38.38 \\
7\end{array}$ & $\begin{array}{c}34.74 \\
6\end{array}$ & 24.284 & 1.298 & 3.728 & 3.624 & 8.014 \\
\hline & Total & $\begin{array}{c}112.0 \\
54\end{array}$ & $\begin{array}{c}152.9 \\
14\end{array}$ & $\begin{array}{c}418.5 \\
90\end{array}$ & $\begin{array}{c}451.4 \\
92\end{array}$ & $\begin{array}{c}247.7 \\
66\end{array}$ & 39.135 & $\begin{array}{c}38.01 \\
8\end{array}$ & $\begin{array}{r}45.17 \\
5\end{array}$ & $\begin{array}{r}12.48 \\
0\end{array}$ & 10.519 \\
\hline \multirow{5}{*}{$\begin{array}{c}\text { Oest } \\
\text { e } \\
\text { SC }\end{array}$} & $\begin{array}{c}\text { Estadu } \\
\text { al }\end{array}$ & 0 & 0 & $\begin{array}{r}27.91 \\
3 \\
\end{array}$ & $\begin{array}{r}62.76 \\
7 \\
\end{array}$ & $\begin{array}{r}45.35 \\
3 \\
\end{array}$ & 1.073 & 6.365 & 9.574 & 156 & 147 \\
\hline & Federal & 0 & 0 & 0 & 0 & 414 & 1.106 & 0 & 73 & 0 & 0 \\
\hline & $\begin{array}{c}\text { Munici } \\
\text { pal }\end{array}$ & $\begin{array}{r}18.06 \\
5 \\
(92,4 \\
\%) \\
\end{array}$ & $\begin{array}{r}29.35 \\
4 \\
(91,6 \\
\%) \\
\end{array}$ & $\begin{array}{r}49.63 \\
7 \\
(60,3 \\
\%) \\
\end{array}$ & $\begin{array}{r}25.36 \\
3 \\
(27,5 \\
\%) \\
\end{array}$ & $\begin{array}{r}75 \\
(0,2 \% \\
)\end{array}$ & $\begin{array}{l}0 \\
-\end{array}$ & $\begin{array}{r}1.536 \\
(18,4 \\
\%)\end{array}$ & $\begin{array}{r}174 \\
(1,7 \% \\
)\end{array}$ & $\begin{array}{r}103 \\
(12,7 \\
\%)\end{array}$ & $\begin{array}{r}119 \\
(8 \%)\end{array}$ \\
\hline & $\begin{array}{c}\text { Privad } \\
\text { a }\end{array}$ & 1.491 & 2.679 & 4.804 & 4.102 & 4.024 & 5.806 & 462 & 241 & 549 & 1.211 \\
\hline & Total & $\begin{array}{r}19.55 \\
6 \\
\end{array}$ & $\begin{array}{r}32.03 \\
3 \\
\end{array}$ & $\begin{array}{r}82.35 \\
4\end{array}$ & $\begin{array}{r}92.23 \\
2 \\
\end{array}$ & $\begin{array}{r}49.86 \\
6 \\
\end{array}$ & 7.985 & 8.363 & $\begin{array}{r}10.06 \\
2 \\
\end{array}$ & 808 & 1.477 \\
\hline
\end{tabular}

Fonte: Inep/Censo Escolar 2010. 
Dados do Anexo I das Resoluções CD/FNDE/n 47/2007 (BRASIL, 2007d) e no 46/2008 (BRASIL, 2008b) evidenciam que, dentre os 1.822 municípios brasileiros considerados prioritários para recebimento de apoio técnico e ou financeiro do MEC, um conjunto de 20 deles pertence à mesorregião oeste de Santa Catarina. Esse conjunto representa aproximadamente $17 \%$ dos municípios da mesorregião e $51 \%$ dos prioritários do estado.

Observando o IDEB da rede pública dos municípios prioritários da mesorregião, verificamos que houve crescimento nos resultados alcançados desde que iniciou a avaliação da educação básica por esse instrumento. Segundo dados divulgados pelo INEP, em 2009 a maioria dos municípios superou a meta prevista para o biênio.

Não obstante, especialmente nos anos finais do ensino fundamental persiste um quadro ainda desafiador. Cinco dos atuais 20 municipios prioritários do oeste catarinense (Coronel Martins, Formosa do Sul, Guatambu, Lebon Regis e São Lourenço do Oeste), ou seja, 25\% deles reduziram seu IDEB em 2009 nos anos finais do ensino fundamental, comparativamente ao alcançado em 2007, ficando alguns abaixo da meta traçada pelo INEP para o biênio. Os dados da Tabela 2 demonstram o resultado do IDEB desses municípios.

Tabela 2: IDEB da rede municipal dos municípios da mesorregião oeste de Santa Catarina considerados prioritários pelo MEC.

\begin{tabular}{|c|c|c|c|c|c|c|}
\hline \multirow[t]{2}{*}{ MUNICÍPIO } & \multicolumn{3}{|c|}{$\begin{array}{c}\text { IDEB } \\
\text { REDE MUNICIPAL } \\
4^{\text {a }} \text { série } / 5^{\circ} \text { ano } \\
\end{array}$} & \multicolumn{3}{|c|}{$\begin{array}{c}\text { IDEB } \\
\text { REDE MUNICIPAL } \\
\text { 8 }^{\text {a }} \text { série } / 9^{\circ} \text { ano } \\
\end{array}$} \\
\hline & 2005 & 2007 & 2009 & 2005 & 2007 & 2009 \\
\hline Calmon & 3,4 & 3,8 & 4,4 & - & - & - \\
\hline Caxambu do Sul & 3,4 & 3,8 & 4,8 & - & 2,6 & 4,5 \\
\hline Coronel Martins & 3,3 & 4,3 & 4,4 & - & - & 3,7 \\
\hline Dionísio Cerqueira & 3,2 & 3,9 & 5,0 & - & - & - \\
\hline Entre Rios & 3,6 & 4,7 & - & - & - & - \\
\hline Formosa do Sul & 3,4 & 3,8 & 4,8 & - & - & - \\
\hline Fraiburgo & 3,6 & 4,6 & 5,2 & 3,5 & 4,0 & 4,6 \\
\hline Galvão & 3,1 & 3,4 & 4,4 & & 3,6 & 4,1 \\
\hline Guatambu & - & 3,5 & 4,1 & - & - & - \\
\hline Iraceminha & 4,4 & 3,8 & 5,6 & - & - & - \\
\hline Lebon Regis & 3,0 & 3,3 & 4,3 & - & 3,8 & 2,7 \\
\hline Lindoia do Sul & 3,6 & 5,1 & 6,2 & - & - & - \\
\hline Marema & 3,2 & 4,4 & 6,3 & - & - & - \\
\hline Ouro Verde & - & 3,8 & 5,7 & - & - & - \\
\hline Santa Terezinha do Progresso & 3,6 & 4,1 & 4,9 & - & - & - \\
\hline São Bernardino & 3,5 & 3,6 & 4,7 & - & - & - \\
\hline São Lourenço do Oeste & 3,3 & 4,4 & 4,8 & 3,8 & 3,8 & 2,4 \\
\hline Tangará & 3,5 & 4,5 & 4,6 & - & - & - \\
\hline Tigrinhos & - & 3,8 & 5,3 & - & 4,1 & - \\
\hline Vargem Bonita & 3,4 & 3,9 & 5,2 & - & - & - \\
\hline
\end{tabular}

Fonte: INEP.

Obs.: Os municípios com (-) na $8^{a}$ série $/ 9^{\circ}$ ano não possuem avaliação do IDEB ou não contam com as séries finais do Ensino Fundamental. 
Como podemos verificar, comparativamente ao IDEB nacional que, em 2005 foi de 3,8 pontos, esses municípios apresentaram baixo índice de desenvolvimento educacional ficando a média do IDEB em 3,06 pontos.

\section{A adesão massiva dos 20 municípios ao Plano de Metas Compromisso Todos pela} Educação e a consequente elaboração do PAR desaguou na celebração de Termos de Cooperação Técnica entre o MEC e os municipios. A vigência desses termos está prevista para até quatro anos (2008-2011). O Termo firmado entre o MEC e cada município tem por objetivo promover as ações e atividades programadas no PAR para o desenvolvimento educacional e para melhorar o seu IDEB, nas quatro dimensões já mencionadas. ${ }^{6}$

A definição de quais ações e atividades constarão do PAR de cada município depende dos resultados do diagnóstico da situação educacional local em relação aos indicadores de cada Área. A pontuação atribuída a cada indicador resulta de uma avaliação que toma em conta um conjunto de descritores. 0 Quadro 2 sintetiza os elementos que constituem os descritores das Áreas 1, 2, 3 e 4, da Dimensão 2.

\section{Quadro 2: Síntese dos descritores de pontuação dos indicadores das Áreas 1 a 4 da Dimensão 2 do PAR}

\begin{tabular}{|l|l|}
\hline Pontuação & Descritores \\
\hline \multirow{5}{*}{ ponto } & $\begin{array}{l}\text { Quando menos de 10\% ou nenhum dos professores: que atuam nas creches e/ou pré- } \\
\text { escola possuem habilitação adequada; e/ou que atuam nos anos/séries iniciais e/ou } \\
\text { anos/séries finais do Ensino Fundamental possuem formação superior em curso de } \\
\text { licenciatura; e/ou que atuam em educação especial, escolas do campo, comunidades } \\
\text { quilombolas ou indigenas participam ou participaram de cursos com formação } \\
\text { especifica para atuação nestas modalidades. Quando não existem politicas voltadas } \\
\text { para a formação continuada dos professores que atuam na Educação Infantil, e/ou } \\
\text { nos anos/séries iniciais e/ou finais do ensino fundamental e/ou para a formação } \\
\text { inicial e continuada dos professores visando o cumprimento da Lei 10.639/03. }\end{array}$ \\
\hline $\begin{array}{l}\text { Quando menos de 50\% dos professores: que atuam nas creches e/ou pré-escola } \\
\text { possuem habilitação adequada; e/ou que atuam nos anos/séries iniciais do Ensino } \\
\text { Fundamental possuem formação superior em curso de licenciatura; e/ou que atuam em } \\
\text { educação especial, escolas do campo, comunidades quilombolas ou indigenas } \\
\text { participam ou participaram de cursos com formação especifica para atuação nestas } \\
\text { modalidades. Quando menos de 30\% dos professores da rede que atuam nos anos/ } \\
\text { séries finais do Ensino Fundamental possuem formação superior na área/ disciplina de } \\
\text { atuação. Quando existem politicas sem implementação, voltadas: para a formação } \\
\text { continuada dos professores que atuam na Educação Infantil (creches e pré-escolas); e/ } \\
\text { ou para a formação continuada dos professores que atuam nos anos/séries iniciais do } \\
\text { Ensino Fundamental que não visam integralmente a melhoria da qualidade de } \\
\text { aprendizagem da leitura/escrita, da matemática e dos demais componentes curriculares; } \\
\text { e/ou para a formação continuada dos professores que atuam nos anos/séries finais do } \\
\text { Ensino Fundamental, mas estas não visam integralmente a melhoria da qualidade de } \\
\text { aprendizagem de todos os componentes curriculares; e/ou para a formação inicial e } \\
\text { continuada dos professores visando o cumprimento da Lei 10.639/03. }\end{array}$ \\
\hline
\end{tabular}

6 O MEC designa como unidades executoras do Termo: o FNDE, a Secretaria de Educação Especial (SEESP), a Secretaria de Educação a Distância (SEED), a Secretaria de Educação Continuada, Alfabetização e Diversidade (SECAD), a Secretaria de Educação Profissional e Tecnológica (SETEC) e a Secretaria de Educação Básica (SEB). 
(continuação)

\begin{tabular}{|c|c|}
\hline 3 pontos & $\begin{array}{l}\text { Quando 50\% ou mais dos professores: que atuam nas creches possuem } \\
\text { habilitação adequada; e/ou que atuam na pré-escola possuem habilitação } \\
\text { adequada. Quando mais de 50\% dos professores: que atuam nos anos/séries } \\
\text { iniciais do Ensino Fundamental possuem formação superior em curso de } \\
\text { licenciatura; e/ou que atuam nos anos/séries finais do Ensino Fundamental } \\
\text { possuem formação superior na área/ disciplina de atuação; que atuam em } \\
\text { educação especial, escolas do campo, comunidades quilombolas ou indigenas } \\
\text { participam ou participaram de cursos com formação específica para atuação } \\
\text { nestas modalidades. Quando existem politicas em fase de implementação, } \\
\text { voltadas: para a formação continuada dos professores que atuam na } \\
\text { Educação Infantil (creches e pré-escolas); e/ou a para a formação continuada } \\
\text { dos professores que atuam nos anos/séries iniciais do Ensino Fundamental } \\
\text { visando a melhoria da qualidade de aprendizagem da leitura/escrita, da } \\
\text { matemática e dos demais componentes curriculares; e/ou para a formação } \\
\text { continuada dos professores que atuam nos anos/séries finais do Ensino } \\
\text { Fundamental, visando a melhoria da qualidade de aprendizagem de todos os } \\
\text { componentes curriculares. Quando existem políticas em fase de } \\
\text { implementação, voltadas para a formação inicial e continuada dos } \\
\text { professores visando o cumprimento da Lei 10.639/03. }\end{array}$ \\
\hline 4 pontos & $\begin{array}{l}\text { Quando todos os professores: que atuam nas creches possuem habilitação } \\
\text { adequada; e/ou que atuam na pré-escola possuem habilitação adequada; e/ou } \\
\text { que atuam nos anos/séries iniciais do Ensino Fundamental possuem formação } \\
\text { superior em curso de licenciatura; e/ou que atuam nos anos/séries finais do } \\
\text { Ensino Fundamental possuem formação superior na área/ disciplina de } \\
\text { atuação; e/ou que atuam em educação especial, escolas do campo, } \\
\text { comunidades quilombolas ou indígenas participam ou participaram de cursos } \\
\text { com formação específica para atuação nestas modalidades. Quando existem } \\
\text { politicas com boa implementação voltadas: para a formação continuada dos } \\
\text { professores que atuam na Educação Infantil (creches e pré-escolas); e/ou para a } \\
\text { formação continuada dos professores que atuam nos anos/séries iniciais do } \\
\text { Ensino Fundamental para a formação continuada dos professores que atuam } \\
\text { nos anos/séries finais do Ensino Fundamental, visando a melhoria da qualidade } \\
\text { de aprendizagem de todos os componentes curriculares; e/ou para a formação } \\
\text { inicial e continuada dos professores visando o cumprimento da Lei 10.639/03. }\end{array}$ \\
\hline
\end{tabular}

Fonte: elaborado com base nos dados em Brasil (2008a).

Com base nesses descritores, os municípios pesquisados realizaram o diagnóstico no tocante às quatro áreas dessa dimensão. 0 Quadro 3 traduz o resultado da avaliação realizada em cada indicador. 
Quadro 3: Síntese por indicador - resultado detalhado da realização do diagnóstico.

\begin{tabular}{|c|c|c|c|c|c|c|c|c|c|c|c|c|c|c|c|c|c|c|c|c|c|c|}
\hline $\begin{array}{l}\text { ÁREA 1Formação } \\
\text { inicial de } \\
\text { Professores da } \\
\text { Educação Básica }\end{array}$ & $\frac{\check{\delta}}{\text { है }}$ & 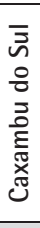 & 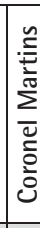 & 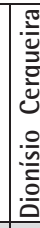 & 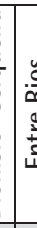 & 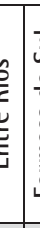 & 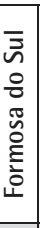 & 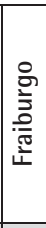 & 疍 & 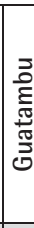 & 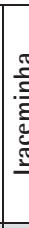 & 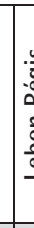 & 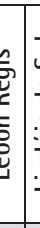 & 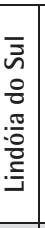 & 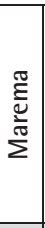 & $\begin{array}{l}\frac{0}{2} \\
\frac{0}{20} \\
\frac{0}{3} \\
0\end{array}$ & 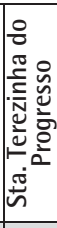 & 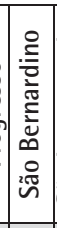 & 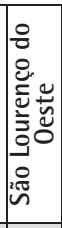 & - & 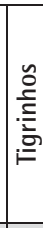 & 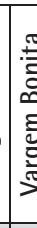 \\
\hline $\begin{array}{l}\text { 1. Qualificação dos } \\
\text { professores que } \\
\text { atuam nas creches }\end{array}$ & 1 & - & 2 & 4 & & 3 & 4 & 3 & 4 & 4 & 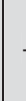 & & 4 & 4 & - & - & 3 & 2 & 4 & 4 & 3 & \\
\hline $\begin{array}{l}\text { 2. Qualificação dos } \\
\text { professores que } \\
\text { atuam na pré- } \\
\text { escola }\end{array}$ & 1 & 4 & 1 & 4 & & 3 & 4 & 3 & 4 & 4 & & & 4 & 4 & 4 & 3 & 1 & 4 & 4 & 4 & 3 & \\
\hline $\begin{array}{l}\text { 3. Qualificação dos } \\
\text { professores que } \\
\text { atuam nas séries } \\
\text { iniciais do ensino } \\
\text { fundamental }\end{array}$ & 2 & 4 & 4 & 4 & & 4 & 4 & 3 & 4 & 4 & & & 3 & 4 & 4 & 3 & 4 & 4 & 4 & 4 & 3 & 4 \\
\hline $\begin{array}{l}\text { 4. Qualificação dos } \\
\text { professores que } \\
\text { atuam nos } \\
\text { anos/séries finais } \\
\text { do ensino } \\
\text { fundamental }\end{array}$ & 1 & 4 & 4 & - & & - & - & 3 & 4 & - & & & 3 & - & - & - & - & - & 4 & 4 & 3 & \\
\hline $\begin{array}{l}\text { ÁREA 2Formação } \\
\text { continuada de } \\
\text { Professores da } \\
\text { Educação Básica }\end{array}$ & $\frac{\bar{\delta}}{\frac{\delta}{\tilde{\varepsilon}}}$ & 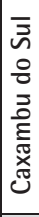 & 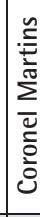 & 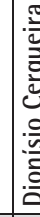 & 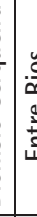 & 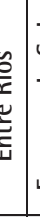 & 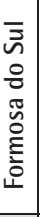 & 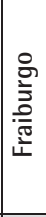 & $\frac{2}{\frac{2}{\pi}}$ & 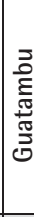 & 吾 & & . & 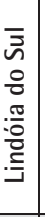 & 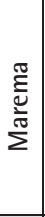 & 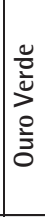 & 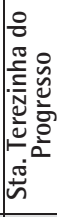 & 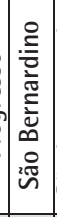 & 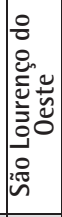 & 倍 & 先 & 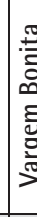 \\
\hline $\begin{array}{l}\text { 1. Existência e } \\
\text { implementação de } \\
\text { políticas para a } \\
\text { formação } \\
\text { continuada de } \\
\text { professores que } \\
\text { atuam na Educação } \\
\text { Infantil }\end{array}$ & 1 & 2 & 1 & 2 & & 2 & 2 & 2 & 1 & 4 & & & 4 & 2 & 4 & 2 & 2 & 4 & 2 & 3 & 2 & 2 \\
\hline $\begin{array}{l}\text { 2. Existência e } \\
\text { implementação de } \\
\text { políticas para a } \\
\text { formação } \\
\text { continuada de } \\
\text { professores, que } \\
\text { visem a melhoria } \\
\text { da qualidade de } \\
\text { aprendizagem da } \\
\text { leitura/escrita e } \\
\text { matemática nos } \\
\text { anos/séries iniciais } \\
\text { do ensino } \\
\text { fundamental }\end{array}$ & 1 & 2 & 1 & 2 & & 2 & 2 & 1 & 1 & 4 & & & 2 & 2 & 2 & 3 & 2 & 2 & 2 & 3 & 2 & 2 \\
\hline
\end{tabular}


(continuação)

\begin{tabular}{|c|c|c|c|c|c|c|c|c|c|c|c|c|c|c|c|c|c|c|c|c|}
\hline $\begin{array}{l}\text { 3. Existência e } \\
\text { implementação de } \\
\text { políticas para a } \\
\text { formação } \\
\text { continuada de } \\
\text { professores, que } \\
\text { visem a melhoria } \\
\text { da qualidade de } \\
\text { aprendizagem da } \\
\text { leitura/escrita e } \\
\text { matemática nos } \\
\text { anos/séries finais } \\
\text { do ensino } \\
\text { fundamental }\end{array}$ & 1 & 1 & 1 & - & - & - & 1 & 1 & - & 3 & 2 & - & - & - & - & - & 2 & 3 & 2 & - \\
\hline $\begin{array}{l}\text { ÁREA 3Formação de } \\
\text { Professores da } \\
\text { Educação Básica } \\
\text { para atuação em } \\
\text { educação especial, } \\
\text { escolas do campo, } \\
\text { comunidades } \\
\text { Quilombolas ou } \\
\text { Indígenas }\end{array}$ & $\frac{\bar{\Xi}}{\frac{\Xi}{\tilde{J}}}$ & 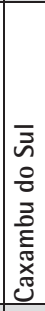 & 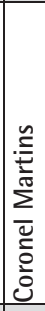 & 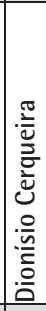 & 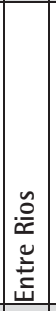 & 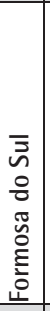 & 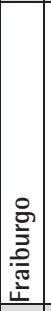 & 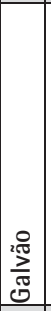 & 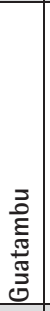 & 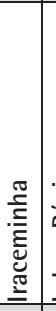 & 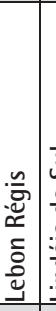 & 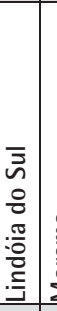 & 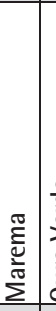 & 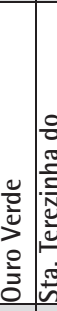 & 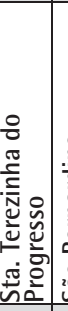 & 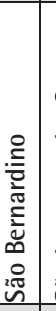 & 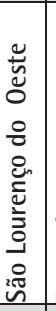 & 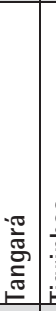 & 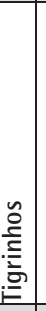 & 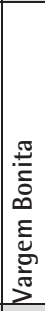 \\
\hline $\begin{array}{l}\text { 1. Qualificação dos } \\
\text { professores que } \\
\text { atuam em educação } \\
\text { especial, escolas do } \\
\text { campo, } \\
\text { comunidades } \\
\text { quilombolas ou } \\
\text { indigenas. }\end{array}$ & 1 & - & - & 1 & 1 & - & 1 & 1 & 1 & 1 & 1 & 1 & - & 2 & 1 & 1 & 2 & - & - & - \\
\hline $\begin{array}{l}\text { ÁREA 4Formação } \\
\text { inicial e continuada } \\
\text { de professores da } \\
\text { Educação Básica } \\
\text { para cumprimento } \\
\text { da Lei } 10.639 / 03\end{array}$ & 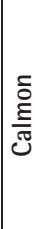 & 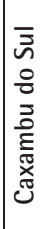 & 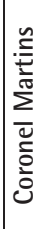 & 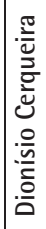 & 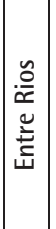 & 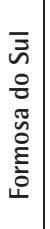 & 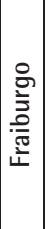 & 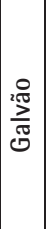 & 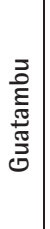 & 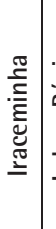 & 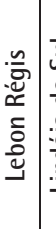 & 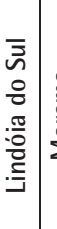 & 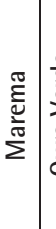 & 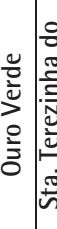 & 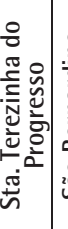 & 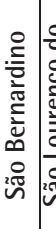 & 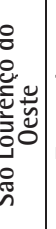 & $\begin{array}{l}\frac{\pi}{\pi} \\
\frac{\pi}{\sqrt{5}} \\
\frac{\pi}{\pi} \\
\frac{\pi}{\pi}\end{array}$ & 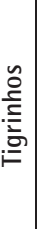 & 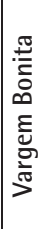 \\
\hline $\begin{array}{l}\text { 1. Existência e } \\
\text { implementação de } \\
\text { políticas para a } \\
\text { formação inicial e } \\
\text { continuada de } \\
\text { professores, que } \\
\text { visem a } \\
\text { implementação da } \\
\text { Lei } 10.639 \text {, de } 09 \\
\text { de janeiro de } 2003 \text {. }\end{array}$ & - & 2 & 4 & 1 & 1 & 1 & 2 & 1 & 3 & 2 & 1 & 1 & 1 & 2 & 1 & 2 & 1 & 2 & 1 & 1 \\
\hline
\end{tabular}

Fonte: elaborado com base em Brasil ([2007]). 
Os dados do Quadro 3 evidenciam que a formação inicial dos professores da educação infantil e do ensino fundamental (Área 1) está praticamente consolidada. Dos 20 municípios da mesorregião, apenas um deles (Calmon) tem avaliação abaixo da média nos indicadores da Área 1.

A sistematização geral da pontuação atribuída pelos municípios a cada um dos descritores das Áreas 1, 2, 3 e 4 que compõem a Dimensão 2 está representada no Gráfico 1.

Gráfico 1: Frequência de pontuação dos indicadores da Dimensão 2 - Formação de Professores e de Profissionais de Serviços e Apoio Escolar - nos PAR dos municípios prioritários da região oeste de Santa Catarina.

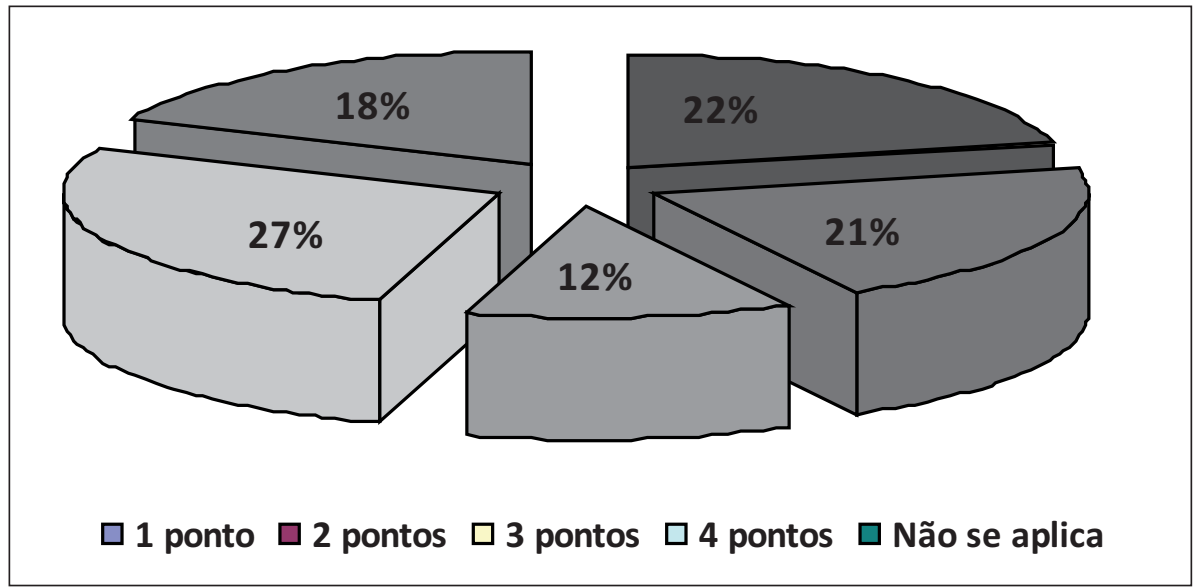

Fonte: elaborado com base em Brasil ([2007]).

Conforme podemos observar, a frequência de pontuação que indica situação insatisfatória (1 e 2) é de 43\%, e a de situação satisfatória (3 e 4) é de 39\%. Ou seja, no conjunto das áreas da Dimensão 2, os municípios da mesorregião sinalizam para importantes lacunas no âmbito da formação de professores.

Diferente do que ocorre na Área 1, dos 20 municípios, 65\% deles apresenta situação insatisfatória (1 e 2 pontos) em relação à existência e implementação de políticas para a formação continuada de professores da educação básica, que compreende a Área 2.

Já nas Áreas 3 e 4, o diagnóstico aponta para uma situação ainda mais preocupante. Isto porque $100 \%$ dos municipios pesquisados avaliaram insatisfatoriamente a qualificação dos professores que atuam em educação especial, escolas do campo, comunidades quilombolas ou indígenas (Área 3). Na Área 4, apenas 2 municípios pontuam satisfatoriamente (3 e 4 pontos) à existência e implementação de políticas para a formação inicial e continuada de professores que visem a implementação da Lei 10.639, de 09 de janeiro de 2003. 
Em relação às ações propostas, o estudo evidencia que dos vinte municípios da mesorregião, dezenove deles previram em seu PAR ações voltadas à formação inicial e continuada dos professores da educação infantil e das séries iniciais. Esses municípios apresentaram um total de 63 ações desdobradas em 240 subações.

Analisando-as comparativamente o total de 63 ações desdobradas em 240 subações relativas à formação de professores, observamos repetição acentuada delas nos municípios do corpus. Porquanto haja repetição de ações, é possível agrupá-las em apenas 8 ações dentre as quais efetivamente podem ser vislumbradas características diferenciadas, conforme consta do Quadro 4.

Quadro 4: Ações de formação docente apresentadas pelos municípios prioritários da mesorregião oeste de Santa Catarina nos PAR

\begin{tabular}{|c|c|}
\hline ÁREAS & AÇÕES \\
\hline $\begin{array}{l}\text { 1. Formação inicial de } \\
\text { Professores da Educação } \\
\text { Básica }\end{array}$ & $\begin{array}{l}\text { i) Assegurar o acesso à formação mínima exigida em Lei a todos os } \\
\text { professores que atuam nas creches; } \\
\text { ii) Assegurar o acesso à formação mínima exigida em Lei a todos os } \\
\text { professores que atuam na pré-escola; } \\
\text { iii) Assegurar o acesso à formação mínima exigida em Lei a todos os } \\
\text { professores que atuam nos anos/séries iniciais do ensino fundamental. }\end{array}$ \\
\hline $\begin{array}{l}\text { 2. Formação continuada de } \\
\text { Professores da Educação } \\
\text { Básica }\end{array}$ & $\begin{array}{l}\text { iv) Implementar políticas de formação continuada dos professores } \\
\text { que atuam na Educação Infantil (çeches e pré-escolas), considerando } \\
\text { a Lei } 10.639 \text { e os principios preconizados pelas Diretrizes Operacionais } \\
\text { para a Educação Básica nas Escolas do Campo; } \\
\text { v) Formular e implementar politicas voltadas para a formação } \\
\text { continuada de professores que atuam nos anos/séries iniciais do } \\
\text { ensino fundamental, considerando, também, as especificidades das } \\
\text { escolas do campo, em particular nas escolas do campo, em particular } \\
\text { as escolas de organização multietária ou multisseriada e as áreas } \\
\text { temáticas, tais como educação ambiental, educação para os direitos } \\
\text { humanos, educação integral; } \\
\text { vi) Formular e implementar políticas voltadas para a formação } \\
\text { continuada dos professores que atuam nos anos/séries finais do } \\
\text { ensino fundamental visando integralmente à melhoria da qualidade } \\
\text { de aprendizagem da leitura/escrita e matemática, considerando, } \\
\text { também, as especificidades das escolas do campo além das seguintes } \\
\text { áreas temáticas: educação ambiental, educação para os direitos } \\
\text { humanos, educação integral e integrada. }\end{array}$ \\
\hline $\begin{array}{l}\text { 3. Formação de Professores } \\
\text { da Educação Básica para } \\
\text { atuação em educação } \\
\text { especial, escolas do campo, } \\
\text { comunidades Quilombolas ou } \\
\text { Indigenas }\end{array}$ & $\begin{array}{l}\text { vii) Promover programas de formação e habilitação especifica para } \\
\text { professores que atuam em educação especial, em escolas do campo, } \\
\text { em comunidades quilombolas e em comunidades indigenas, e que } \\
\text { contemplem também as temáticas: educação ambiental, educação } \\
\text { para os direitos humanos, educação integral e integrada. }\end{array}$ \\
\hline $\begin{array}{l}\text { 4. Formação inicial e } \\
\text { continuada de professores da } \\
\text { Educação Básica para } \\
\text { cumprimento da Lei } 10.639 / 03\end{array}$ & $\begin{array}{l}\text { viii) Desenvolver plano de formação continuada de professores da } \\
\text { educação básica visando ao cumprimento da Lei 10.639/03. }\end{array}$ \\
\hline
\end{tabular}

Fonte: elaborado com base em Brasil ([2007]). 
Das 240 subações originadas das 63 ações da Dimensão 2, 60\% delas contemplam propostas de formação continuada de professores. 0 dado pode ser mais bem visualizado no Gráfico 2, que sintetiza o conjunto das subações propostas pelos municípios para as quatro áreas.

Gráfico 2: Distribuição das subações em quatro Áreas da Dimensão 2.

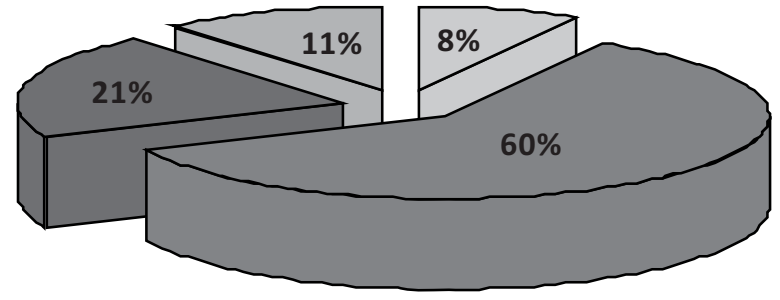

Área 1

Área 2

Área 3

Área 4

Fonte: elaborado com base nos dados do SIMEC (BRASIL, [2007]).

0 foco principal das subações recai sobre a formação continuada (Área 2), justamente uma área para a qual o Estado ainda não prevê muitos investimentos. Embora algumas iniciativas tenham sido empreendidas por meio da Universidade Aberta do Brasil (UaB) e da Plataforma Freire, indubitavelmente, o foco principal da política do governo federal ainda é a formação inicial.

No âmbito da execução das ações e subações, o formulário do PAR apresenta 4 variações: i) realizadas com assistência técnica do MEC; ii) executadas pelo município; iii) realizadas com assistência técnica do MEC e executadas pelo município; iv) sem indicação de responsabilidade de execução. Essas possibilidades de execução explicitam o nível de envolvimento e responsabilização do MEC e dos municípios na efetivação das metas, ações e subações.

Nas 63 ações previstas pelos municípios amostrados, a forma de execução de 16 delas fica somente ao encargo do MEC e contemplam 19 subações; em 11 delas a execução está ao encargo dos municípios para as quais foram estabelecidas 15 subações; 36 ações são desenvolvidas em parceria entre o MEC e os municípios, estas subdivididas em 165 subações.

Ressaltamos que, como texto comum, o Termo de Cooperação Técnica, firmado entre MEC e o município define que a efetividade das ações assumidas pelo MEC/ FNDE está condicionada à disponibilidade orçamentário-financeira, assim como às circunstâncias impeditivas ao cumprimento do que está estabelecido no Termo firmado (BRASIL, [2007]). 
Considerando que a parceria do MEC restringe-se, quase que exclusivamente, à assessoria técnica e não à financeira, pode-se constatar que um percentual de $74,6 \%$ das subações previstas no PAR está sob a responsabilidade de execução dos municípios. $\mathrm{Na}$ análise das subações, verifica-se, portanto, atuação mais significativa do MEC naquelas que dizem respeito à proposição e implantação de políticas. Ou seja, a despeito de todo o empenho para assegurar o repasse de verbas para a implementação das ações, pode ocorrer de o município ter de buscar outras fontes para a execução e implementação das ações com as quais se comprometeu.

\section{Considerações finais}

As constatações aqui apresentadas e o quadro no qual elas se inscrevem nos levam a indagar sobre as reais possibilidades de avanços na formação e valorização dos profissionais do magistério público. Ao mesmo tempo, indagar sobre a eficácia dos programas e ações destinados a alcançar uma educação de qualidade para todos, em vista das dificuldades financeiras dos municípios na implementação das ações consideradas prioritárias.

Entendemos que o modus operandi do PAR, configurado por um rol limitado de ações que podem ser escolhidas e desenvolvidas pelos municípios a partir do diagnóstico prévio, também padronizado, demonstra a tentativa de o Estado tomar para si o controle das iniciativas de formação do magistério no nivel local, embora a responsabilização pelos resultados recai, de forma inexorável, sobre os municípios. Por sua idealização política e configuração técnica, o PAR apresenta-se como um instrumento institucional de regulação do Estado sobre os municípios.

A homogeneização de ações em todos os municípios torna difícil o atendimento às singularidades de cada um, desfavorecendo, com isso, possibilidades de superação dos baixos indicadores educacionais. Por outro lado, a despeito da centralidade que o PAR ocupa no PDE, não se trata de admitir que a eficácia do controle operado sobre as ações inviabilize a implementação de projetos educacionais construídos a partir da realidade de cada município.

Desse modo, projeta-se a necessidade de ampliação das discussões sobre possibilidades de os municípios suplantarem a submissão à regulação operada pelo Estado, bem como de promover o desenvolvimento educacional almejado. Isso implica considerar as condições de indução operadas pelo Estado através do PDE, bem como o contexto político-institucionais de cada município. 


\section{Referências}

ARRETCHE, M. T. S. Políticas sociais no Brasil: descentralização em um Estado federativo. Revista Brasileira de Ciências Sociais, São Paulo, v. 14, n. 40, p. 111-141, jun. 1999.

AZEVEDO, J. M. Lins de. Implicações da nova lógica da ação do Estado para a educação municipal. Educação \&t Sociedade, Campinas, v. 23, n. 80, p. 49-71, set. 2002.

BARROSO, J.; VISEU, S. A emergência de um mercado educativo no planejamento da rede escolar: de uma regulação pela oferta a uma regulação pela procura. Educação \&t Sociedade, Campinas, v. 24, n. 84, p.897-921, set. 2003.

- Os novos modos de regulação das políticas educativas na Europa: da regulação do sistema a um sistema de regulações. Educação em Revista, Belo Horizonte, n. 39. p.19-28, jul. 2004.

. 0 Estado, a educação e a regulação das políticas públicas. Educação $\&$ Sociedade, Campinas, v. 26, n. 92, p. 725-749, out. 2005.

BRASIL. Decreto n 6.094, de 24 de abril de 2007. Dispõe sobre a implementação do Plano de metas compromisso todos pela Educação, pela União Federal, em regime de colaboração com municípios, Distrito Federal e estados, e a participação das famílias e da comunidade, mediante programas e ações de assistência técnica e financeira, visando a mobilização social pela melhoria da qualidade da educação básica. Diário Oficial [da] República Federativa do Brasil, Brasília, DF, 25 de abril de 2007b.

- Ministério da Educação. Compromisso todos pela educação: passo-apasso. Brasilia, DF: MEC, [2008]. Disponivel em: <http://sceweb.mec.gov.br/ termo/action/livreto.pdf>. Acesso em: 23 abr. 2009.

. Ministério da Educação. Fundo Nacional de Desenvolvimento da Educação. Resolução CD/FNDE n 29, de 20 de junho de 2007. Estabelece os critérios, os parâmetros e os procedimentos para a operacionalização da assistência financeira suplementar a projetos educacionais, no âmbito do Compromisso Todos pela Educação, no exercício de 2007. Legis/ação, Brasília, DF, 2007c. Disponível em: < http://www.fnde.gov.br/index.php/leg-res-2007>. Acesso em: 8 mar. 2010.

- Ministério da Educação. Fundo Nacional de Desenvolvimento da Educação. Resolução CD/FNDE nº 47, de 2 de setembro de 2007. Altera a Resolução CD/FNDE nº 29, de 20/7/2007, que estabelece os critérios, os parâmetros e os procedimentos para a operacionalização da assistência financeira suplementar e voluntária a projetos educacionais, no âmbito do Compromisso Todos pela Educação, no exercício de 2007. Legis/ação, Brasilia, DF, 2007d. Disponível em: < http://www.fnde.gov.br/index.php/leg-res-2007>. Acesso em: 8 mar. 2010. 
. Ministério da Educação. Fundo Nacional de Desenvolvimento da Educação.

Resolução CD/FNDE n 46, de 31 de outubro de 2008. Altera a Resolução CD/FNDE n² 29, de 20 de julho de 2007, que estabelece os critérios, os parâmetros e os procedimentos para a operacionalização da assistência financeira suplementar e voluntária a projetos educacionais, no âmbito do Compromisso Todos pela Educação. Brasilia, DF, 2008b. Disponível em: <http:/ /www.fnde.gov.br/index.php/leg-res-2008>. Acesso em: 8 mar. 2010.

. Ministério da Educação. Guia prático de ações. Brasília, DF: MEC, $2009 b$.

Ministério da Educação. Orientações gerais para a elaboração do Plano de Ações Articuladas (PAR) dos municípios. rev. ampl. Brasilia/DF: MEC, 2009a.

Disponivel em: <www.simec.mec.gov.br/ mostra_arquivo.php?id=247919\&tela_login=1>. Acesso em: 26 mar.2010.

Ministério da Educação. PAR: relatório público. Brasília, DF: [2007]. Disponível em: <http://simec.mec.gov.br/cte/relatoriopublico/principal.php >. Acesso em: 8 mar. 2010.

Ministério da Educação. Plano de desenvolvimento da educação: razões, princípios e programas. Brasilia, DF: MEC, 2007a.

. Ministério da Educação. Plano de metas compromisso todos pela educação: instrumento de campo. Brasília, DF: MEC, 2008a. Disponível em: <http:// portal.mec.gov.br/arquivos/pdf/diagnostico.pdf>. Acesso em: 26 mar. 2010.

CASTRO, A. M. D. A. Gerencialismo e educação: estratégias de controle e regulação da gestão escolar. In: CABRAL, A. et al. (Org.). Pontos e contrapontos da política educacional: uma leitura contextualizada de iniciativas governamentais. Brasília: Liber Livro, 2007. p. 115-144.

COHN, A. Os governos municipais e as políticas sociais. In: SOARES, J. A.; CACCIA-BAVA, S. (Org.). Os desafios da gestão municipal democrática. São Paulo: Cortez, 1998. p. 143-192.

KRAWCZYK, N. R. Políticas de regulação e mercantilização da educação: socialização para uma nova cidadania? Educação \& Sociedade, Campinas, v. 26, n. 92, p. 799-819, out. 2005.

MAROY, C. Em direção a uma regulação pós-burocrática dos sistemas de ensino na Europa? In: OLIVEIRA, D. A.; DUARTE, A. (Org.). Políticas públicas e educação: regulação e conhecimento. Belo Horizonte: Fino Traço, 2011. 
MARTINS, A. M. A descentralização como eixo das reformas do ensino: uma discussão da literatura. Educação \&t Sociedade, Campinas, v. 22, n. 77, p. 28-48, dez. 2001.

MOVIMENTO TODOS PELA EDUCAÇÃO. Institucional: quem somos. [2006]. Disponivel em: <http://www.todospelaeducacao.org.br/institucional/quemsomos>. Acesso em: 23 abr. 2011.

OLIVEIRA, D. A. Regulação das políticas educacionais na América Latina e sua consequências para os trabalhadores docentes. Educação \& Sociedade, Campinas, v. 26, n.92, p. 753-775, out. 2005.

SAVIANI, D. 0 plano de desenvolvimento da educação: análise do projeto do MEC. Educação \&t Sociedade, Campinas, v. 28, n.100, p. 1231-1255, out. 2007.

PDE está em cada escola. Nova Escola: gestão escolar. ago./set. 2009.

Disponivel em: <http://revistaescola.abril.com.br>. Acesso em: 17 set. 2010. 